\title{
Mucosal bridge as a cause of dysphagia after surgery for esophageal atresia
}

\author{
L Chapuy MD, M Pomerleau RN, P Perrault RN, C Faure MD
}

\section{CASE PRESENTATION}

Esophageal atresia (EA) is a congenital disorder that affects one in 2500 newborns (1). In the long-term follow-up of these patients, dysphagia is a frequent complication after EA repair. The authors describe three patients presenting with dysphagia after surgical repair of type $\mathrm{C}$ EA for whom a treatable cause was found. Two of these patients underwent surgical correction on the first day of life, which was complicated by an anastomotic leak. In the third patient, surgery was postponed to five months of life due to low birth weight and prematurity, rendering reanastomosis technically difficult. All three patients underwent a barium swallow due to persistent dysphagia at six, 13 and 15 years of age, respectively. Esophageal diverticulae were present in two patients, but none had esophageal strictures (Figure 1). Upper endoscopy revealed a mucosal bridge slightly above the anastomotic site (Figure 2). Two patients showed dramatic improvement of their dysphagia after resection of the mucosal bridge using argon plasma coagulation (Figure 3). The mucosal bridge was not excised in the third patient, whose dysphagia remained.

\section{DISCUSSION}

The etiology of these mucosal bridges is unclear, but may be a consequence of surgery, trauma from nasogastric tube placement (2) or gastroesophageal reflux disease (3). Alternatively, mucosal bridges may also be a consequence of inflammation (4) caused by chronic food stasis due to esophageal dysmotility, which was present in all three of our patients, as confirmed by manometric studies (5).

\section{CONCLUSION}

In the setting of dysphagia after surgical repair of EA, the resection of esophageal mucosal bridges appears to be efficacious in improving dysphagia.

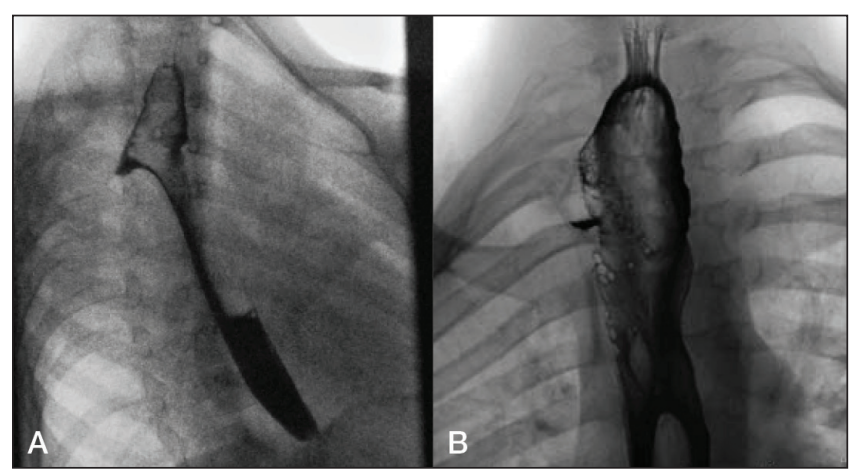

Figure 1) Barium swallow in patient 1 (A) and patient 2 (B). Diverticulae but no strictures are apparent in both patients

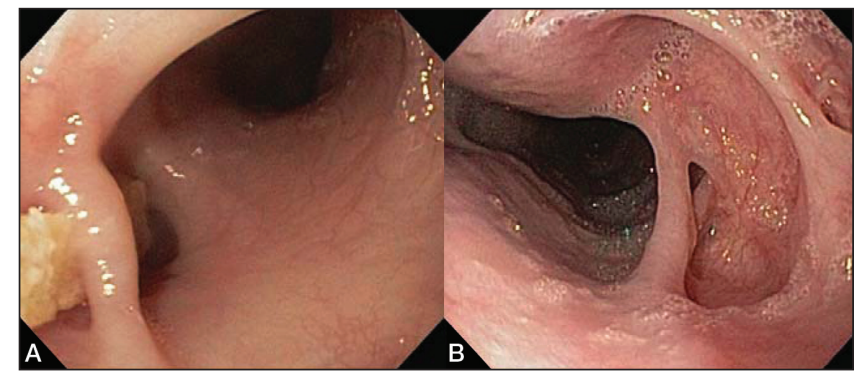

Figure 2) Endoscopic views of mucosal bridge (A) with food remnant in patient 1 . B In proximity to a diverticulum in patient 2

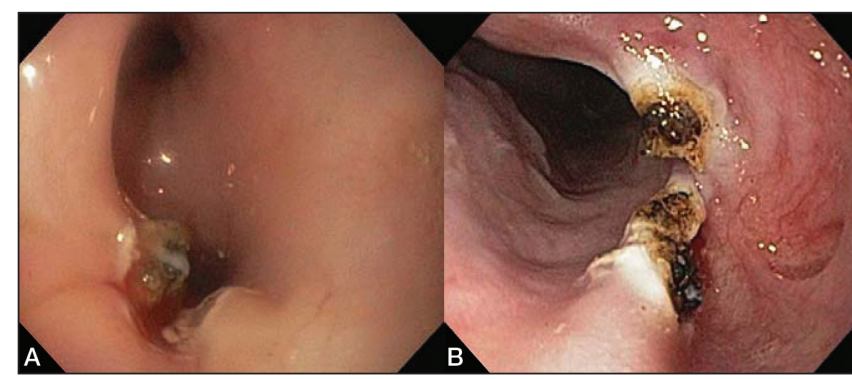

Figure 3) Endoscopic views after resection of mucosal bridge using argon plasma coagulation in patients 1 (A) and 2 (B)

DISCLOSURES: The authors have no financial disclosures or conflicts of interest to declare.

\section{REFERENCES}

1. Spitz L. Oesophageal atresia. Orphanet J Rare Dis 2007;11;2:24

2. Buchman AL, Waring JP. Mucosal bridge formation in the esophagus caused by injury from a nasoenteric feeding tube. J Parenter Enteral Nutr 1994;18:278-9.

3. Abbas MI, Wilson CC, Biko DM, et al. Esophageal mucosal bridge in a 7 year-old. J Pediatr Gastroenterol Nutr 2012;58:e1.

4. Honda S, Sugimoto K, Iwasaki H, et al. Multiple mucosal bridge formation in the esophagus in a patient with Crohn's disease. Endoscopy 1998;30:S37-8.

5. Lemoine C, Aspirot A, Le Henaff G, et al. Characterization of esophageal motility following esophageal atresia repair using highresolution esophageal manometry. J Pediatr Gastroenterol Nutr 2013;56:609-14.

The Canadian Journal of Gastroenterology $\mathcal{E}$ Hepatology is now considering a limited number of submissions for IMAGE OF THE MONTH. These are based on endoscopic, histological, radiological and/or patient images, which must be anonymous with no identifying features visible. The patient must consent to publication and the consent must be submitted with the manuscript. All manuscripts should be practical and relevant to clinical practice, and not simply a case report of an esoteric condition. The text should be brief, structured as CASE PRESENTATION and DISCUSSION, and not more than 700 words in length. A maximum of three images can be submitted and the number of references should not exceed five. The submission may be edited by our editorial team.

Division of Gastroenterology, Department of Pediatrics, CHU Ste-Justine, Montreal, Quebec

Correspondence: Dr Christophe Faure, Division of Gastroenterology and Nutrition, Hôpital Sainte-Justine, 3175 Côte Sainte-Catherine, Montréal,

Québec H3T 1C5. Telephone 514-345-4931 ext 2561, fax 514-345-4999, e-mail christophe.faure@umontreal.ca

Received for publication May 16, 2014. Accepted June 16, 2014 


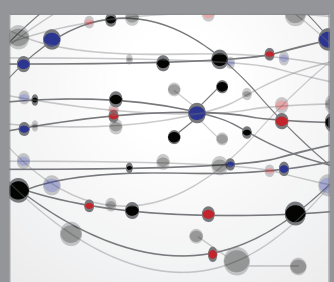

The Scientific World Journal
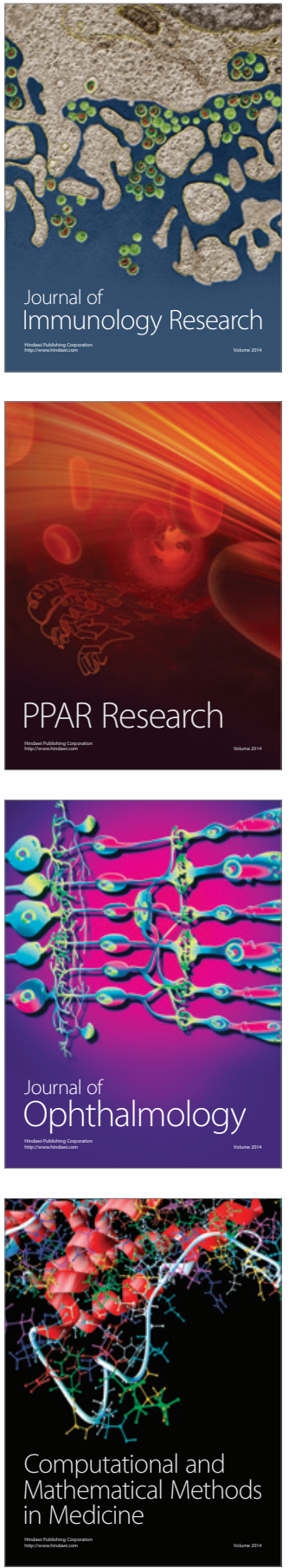

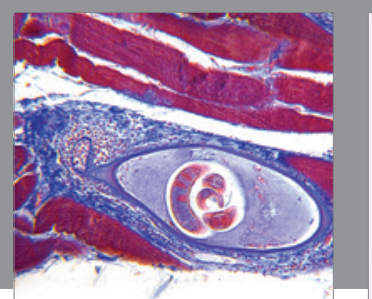

Gastroenterology Research and Practice

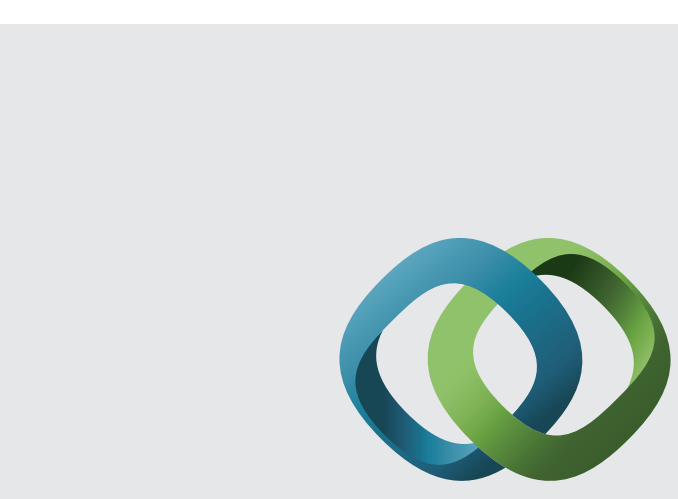

\section{Hindawi}

Submit your manuscripts at

http://www.hindawi.com
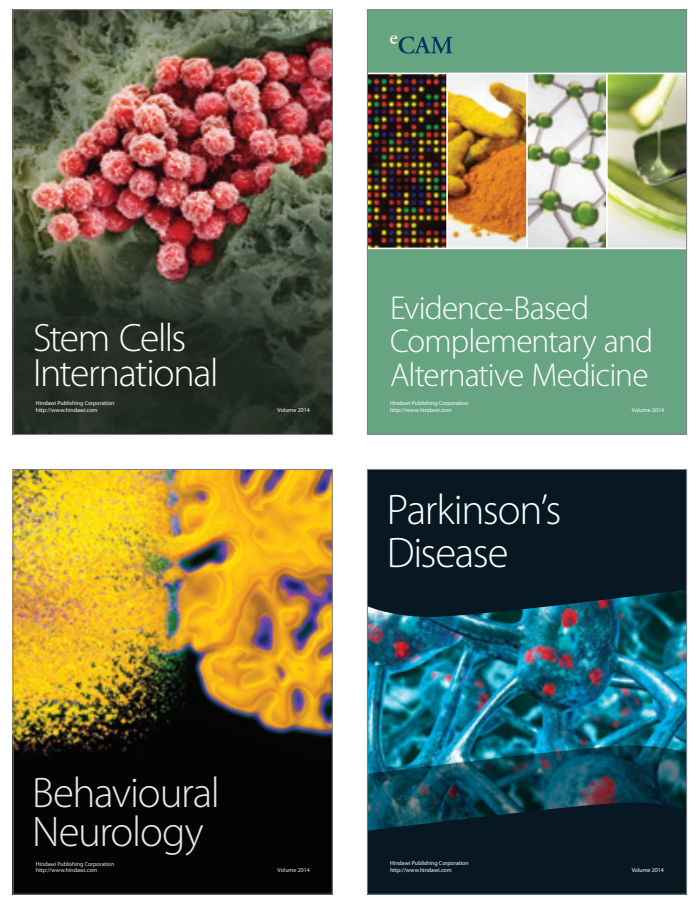
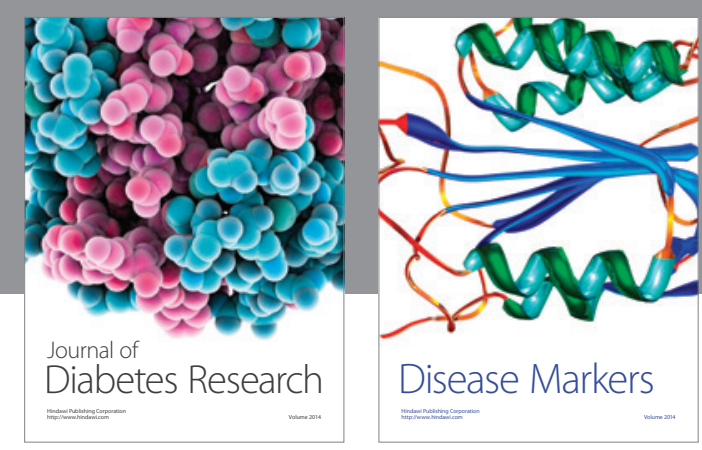

Disease Markers
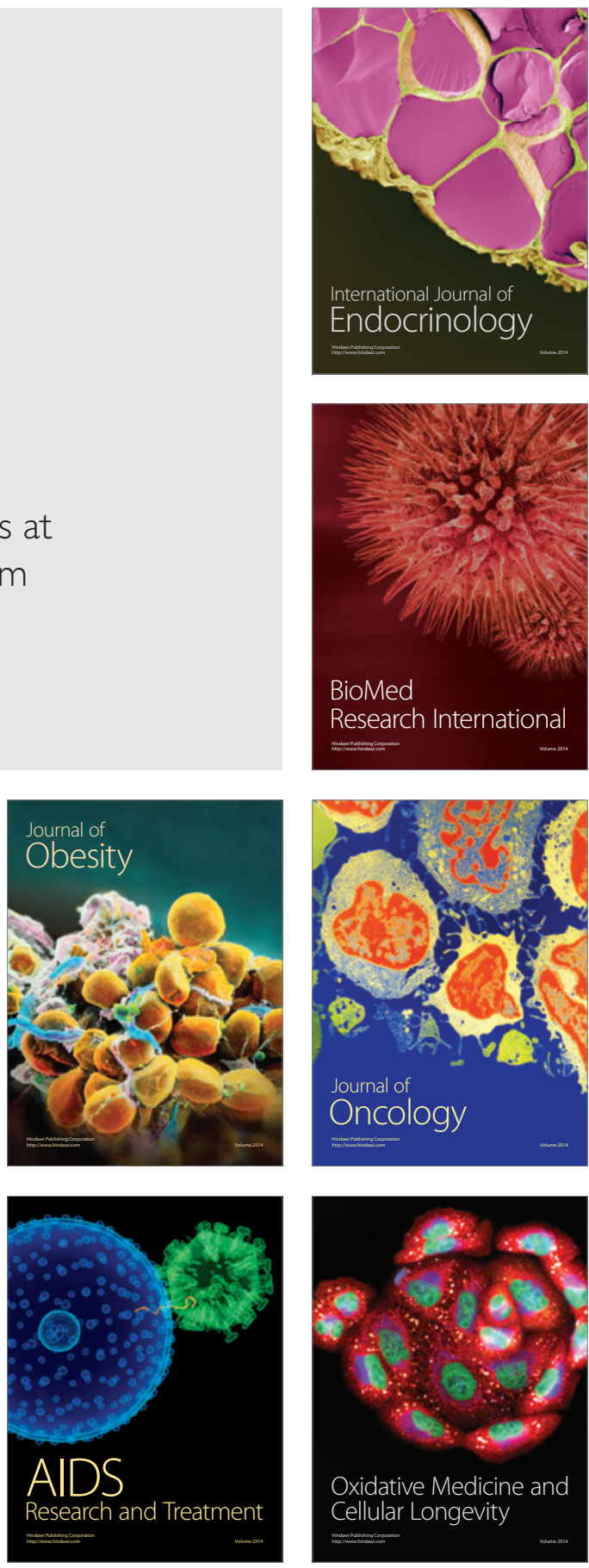